\title{
DC-Link Based Micro-grid System
}

\author{
Miro Milanovič, Mitja Truntič, Miran Rodič \\ University of Maribor; FERI, SI-2000 Maribor, Slovenia \\ Email:miran.rodic@uni-mb.si,miro.milanovic@um.si,mitja.truntic@uni-mb.si
}

Received April, 2013

\begin{abstract}
Design and evaluation of dynamic model of multi-input/multi-output power converter consisting of six converters connected by dc-link will be presented in the paper. The model was created in Matlab/Simulink based on the existing system, with the goal of evaluating various power management strategies, where only transient behavior in case of changed operating regime is of interest. In future the model will be used as a Software-In-the-Loop development tool for the design of supervisory control algorithms.
\end{abstract}

Keywords: Power Management; Power Electronics; Simulation; Modeling; Control

\section{Introduction}

In many applications there is a requirement for multiple power sources to be connected together, providing the power for a single or multiple loads. For example in electric and hybrid vehicles, distributed generation systems etc., multiple sources of electric energy are available, which have to be connected together in order to maximize the efficiency of the overall system under the different operating conditions.

This kind of operation has recently achieved a wide attention due to the extensive use in the electric and hybrid vehicles [1,2], as well as in the distributed $[3,4]$ and micro-generation systems $[5,6]$. Especially the use in alternative and renewable sources utilization can be counted among the most interesting applications $[4,6]$, [7]. Due to the nature of this kind of systems, the supervisory control is required, especially for the performance of power and energy management [8-10]. However, the converters of that complexity become relatively hard to manage, and in the early stage of development, a lot of attention has to be given to the safety of the operation, which has to be set to a much higher level than the one required in the normal operation. Thus the possibilities of testing new algorithms are limited and information obtained is in many cases not sufficient. In development of modern industrial applications simulations are an efficient tool, but applied simulation models have to be precise enough to ensure reliable results and at the same time not too complex in order to allow them to be performed in a reasonable time on the available computers, which in our case are PCs.

In the presented case a multi-input/multi-output power converter was modeled and simulated. The paper will be organized in the way, which will allow the insight into the bottom-up development of the model. After short introduction a complete system will be presented briefly, to give a basic idea of the model requirements. This will be followed by the presentation of the applied converters and their models. In the next step interconnection of the converters will be presented and explained. Next stage will be the presentation of the supervisory control. This is the main purpose of the model, thus it will be presented in more details. Example of a simple supervisory control will be described together with its presentation by the means of state automata in Matlab/Simulink Stateflow tool and then the results will be presented, first experimental and afterwards numerical (simulation) ones. Finally, the conclusion will summarize the paper and give some ideas for the future work.

\section{System Model}

Multi-input/multi-output converter consists of six converter units (C1-C6), which are connected into the system using the DC link (Figure 1). Three bi-directional $(\mathrm{C} 2, \mathrm{C} 3$ and $\mathrm{C} 4)$ and three unidirectional $(\mathrm{C} 1, \mathrm{C} 5$ and $\mathrm{C} 6)$ converter units (in the terms of energy exchange) are used. For the short-term transfer operation system is supported by the capacitor banks applied at the DC-link sides of all converters. The modularity of the system was an important issue due to the demands set, where special attention was on the maintenance. Possibility to exchange both power and controller hardware units was required. As it can be seen from converter schemes in Figures 2 (a)-(f), there are the equal half-bridge units used as basic power electronics blocks. Based on this requirement the power (Figure 3(a)) and microcontroller 
module for each converter and for supervisory system (Figure 3(b)) are designed.

Control hardware units are exchanging data using CAN bus. The control is performed in two levels, a low level control applied to each of the converters, so called single converter control, and a supervisory level control. In both levels hybrid control approaches have to be applied due to the required controlled operation in different operation modes.

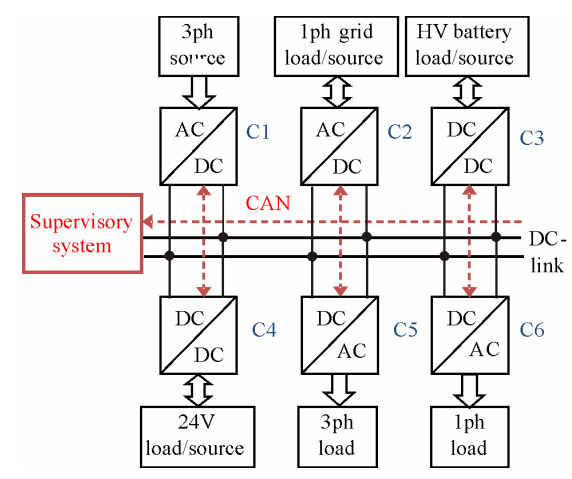

Figure 1. System layout.

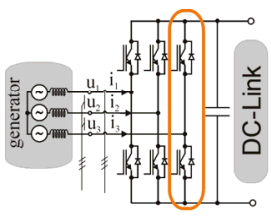

(a)

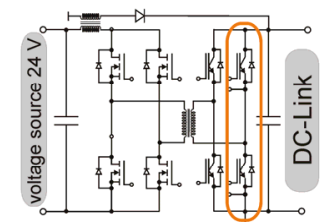

(d)

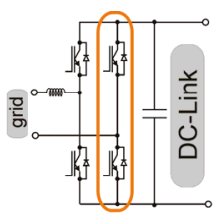

(b)

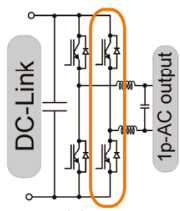

(e)

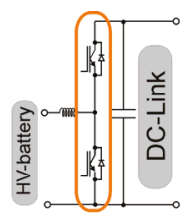

(c)

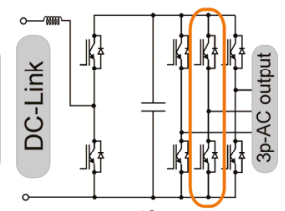

(f)
Figure 2. Converters in system; (a) AC-DC converter-C1, (b) AC-DC converter-C2; (b) DC-DC converter-C3; (e) DC-DC converter-C4; (e) DC-AC converter-C5; (f) DC-DC-AC converter-C6.

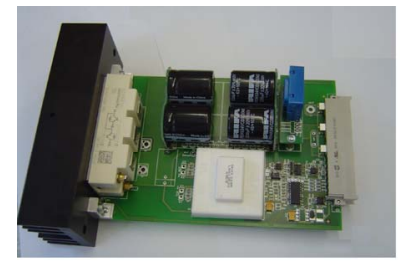

(a)

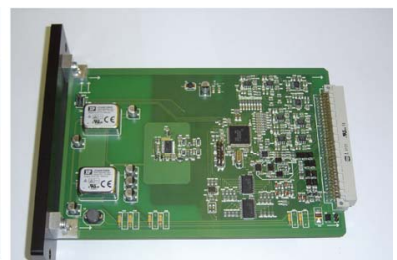

(b)
Figure 3. (a) Power module, (b) DSP module.

\subsection{Modelling of Converter Units}

In the modeling of converter units the complexity is reduced to the level of single converter. It is assumed that the converter is operating in failure-free operation. Thus only the turning of converter on and off is introduced into the hybrid model besides the transient behavior of the current controlled converter under normal operation. The most-inner control loop of the inverter is the current controller. In presented case PI control algorithm has been used, due to its simplicity and relatively high robustness. The converter control scheme, which enables operation as voltage and current controller, is presented in Figure 4. The switching between the voltage and current control can be presented by the use of simple switch, $S_{C x}$. For the sake of simplicity only C3 will be considered. The model of the current controlled bi- directional converter is shown in Figure 5. The converter is modeled by the transfer functions for operation as a load or source. Additionally, delays are introduced representing the time-delay at starting and stopping of the converter. Such a representation is possible, because in order to increase the safety of the converter system operation, the current has to be zero before operation can be switched between the load and source mode.

Likewise unidirectional converters are also modeled in a similar way, as presented in Figure 6 and Figure 7. Since the control, due to the complexity and spatial distribution, cannot be performed with a centralized algorithm, a distributed control is applied. For that purpose all the converters, which can act as sources $(\mathrm{C} 1, \mathrm{C} 2, \mathrm{C} 3$ and $\mathrm{C} 4$ ), have control as shown in Figure 4. The model of such presented converter is presented in Figure 8. One of the converters (master) should be voltage controlled, while others must be current controlled.

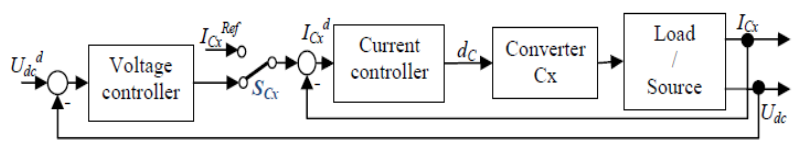

Figure 4. Single converter control scheme.

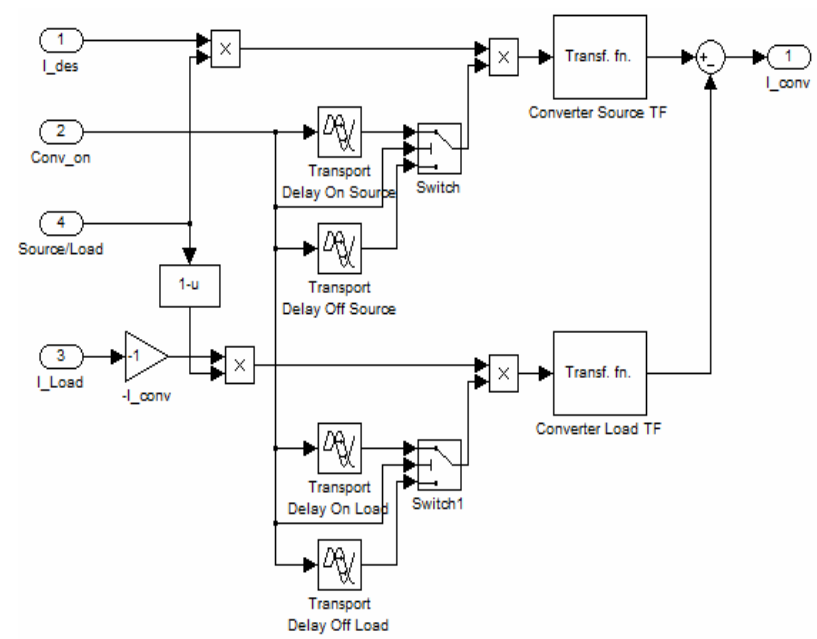

Figure 5. Simulink model of bi-directional current controlled converter. 


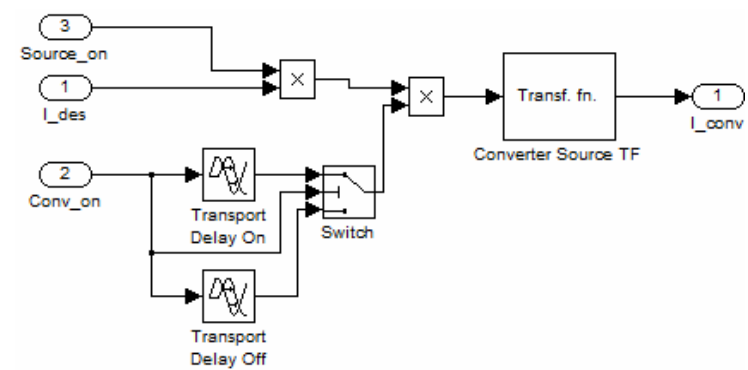

Figure 6. Model of uni-directional (pure source) converter.

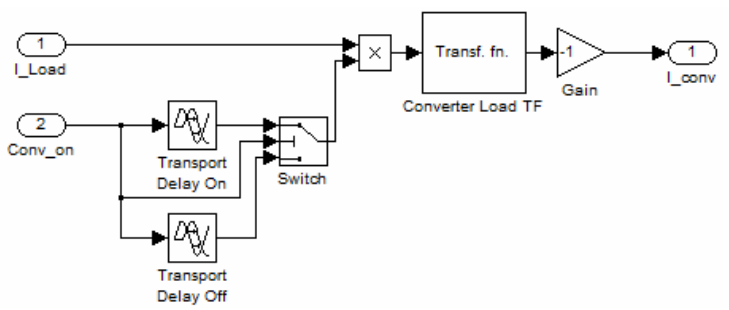

Figure 7. Model of uni-directional (pure load) converter.

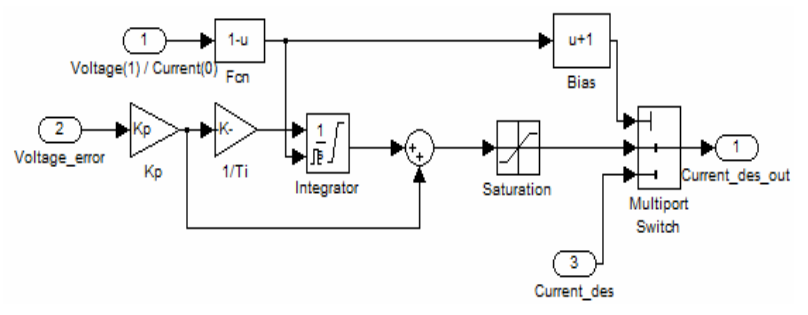

Figure 8. Simulink model of voltage control algorithm.

\subsection{Modeling of Converters Interaction}

The current balance of the DC-link is calculated based on the well-known Kirchhoff formula:

$$
\sum_{k=1}^{6} i_{C k}=0
$$

where $i_{C k}$ denotes the current of $k$-th converter from/to DC-link. Simulink model of the current interconnection is featured in Figure 9, making it possible to attach not only passive, but also active power loads. The basic idea is to enable the replacement of the ideal current source with a more precise converter model in SymPower- Systems (Matlab toolbox), when required. Figure 10 features the Simulink subsystem containing the complete system current dynamics. A better representation is given by:

$$
\frac{d E_{d c}}{d t}=\sum_{k=1}^{6} p_{C k}
$$

where $E_{d c}$ is the DC-link energy, whereas $p_{C k}$ represents the power of the $k$-th converter. If the converter acts as a power source towards the DC-link, the power is represented by positive value, and vice-versa, when the converter acts as a load; the power is represented by negative value.

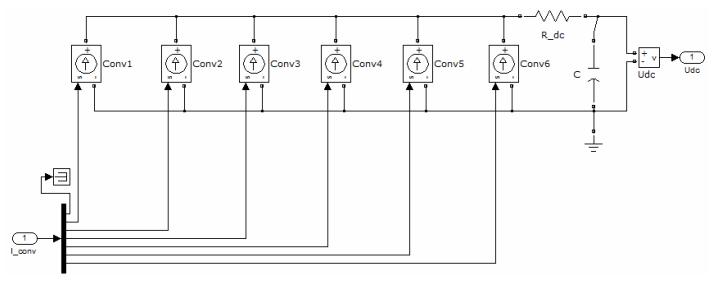

Figure 9. Electrical interconnection of converter units.

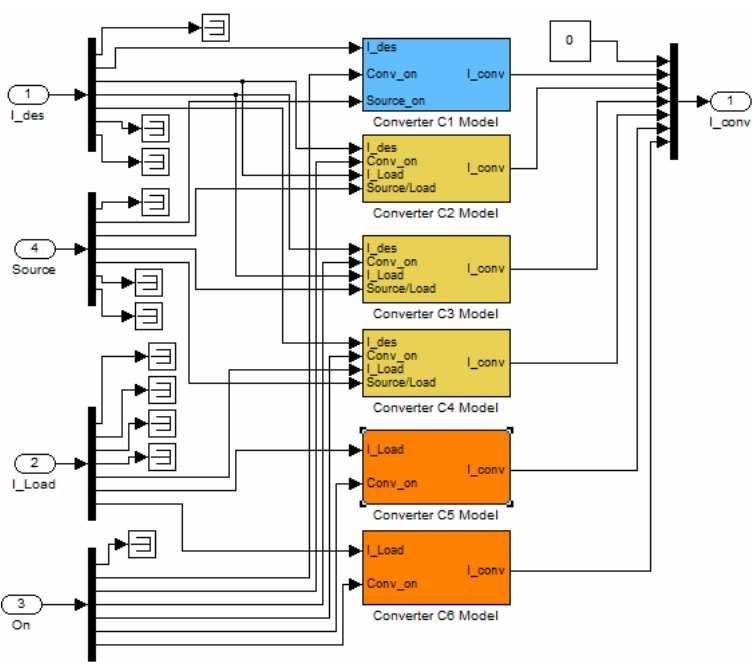

Figure 10. Current dynamics of the converter system.

\subsection{Modelling of Power Management Schemes}

The calculation of currents for the converters connected to remaining sources is performed in the supervisory system based on (1) and (2), together with applied source and load priority schemes. Different operation modes are applied for the system. In each of them there is one primary power source, which presents the main source of energy and also controls the DC-link voltage, and several secondary power sources, of which only provides the additional power into the system. The presentation of the power management states from the viewpoint of the converters' operation is presented in Table 1. The operation as source is denoted by $s$, whereas the operation as load is denoted as $l$. The primary operation is denoted by the capital letter. The priority of the source (where the operation in regenerative mode for short time is not included, like in the case case of converter C5) is presented by the number in superscript, where 0 denotes the primary source and higher priority is represented by the lower number. Additionally, the primary source converter is marked with the gray background. Stateflow model of power management scheme is presented in Figure 11. The states marked by grey backgrounds contain sub-states. Only the ONNET state is presented in more details in Figure 12. An algorithm for the load management is also presented in Figure 13. The State flow representation was used, because it is the simplest 
Table 1. Power Management States - Converter Roles.

\begin{tabular}{cccccccc}
\hline \multirow{2}{*}{ State } & Primary & \multicolumn{6}{c}{ Converter } \\
\cline { 3 - 7 } & source & C1 & C2 & C3 & C4 & C5 & C6 \\
\hline INIT & None & Off & Off & Off & Off & Off & Off \\
STANDBY & None & Off & Off & Off & Off & Off & Off \\
ONNET & Grid & Off & $\mathrm{S}^{0} / 1$ & $\mathrm{~s}^{1} / \mathrm{L}$ & $\mathrm{L}$ & $\mathrm{s} / \mathrm{L}$ & $\mathrm{L}$ \\
NETSUPP & Generator & $\mathrm{S}^{0}$ & $\mathrm{~s} / \mathrm{L}$ & $\mathrm{S}^{1} / 1$ & $\mathrm{~S}^{2} / 1$ & $\mathrm{~s} / \mathrm{L}$ & $\mathrm{L}$ \\
BAT24V & 24 V battery & Off & Off & $\mathrm{s}^{1} / \mathrm{L}$ & $\mathrm{S}^{0} / 1$ & $\mathrm{~s} / \mathrm{L}$ & $\mathrm{L}$ \\
BATTERY & HV battery & Off & Off & $\mathrm{S}^{0} / 1$ & $\mathrm{~L}$ & $\mathrm{~s} / \mathrm{L}$ & $\mathrm{L}$ \\
ISLAND & Generator & $\mathrm{S}^{0}$ & Off & $\mathrm{S}^{1} / 1$ & $\mathrm{~L}$ & $\mathrm{~s} / \mathrm{L}$ & $\mathrm{L}$ \\
FAULT & None & Off & Off & Off & Off & Off & Off \\
\hline
\end{tabular}

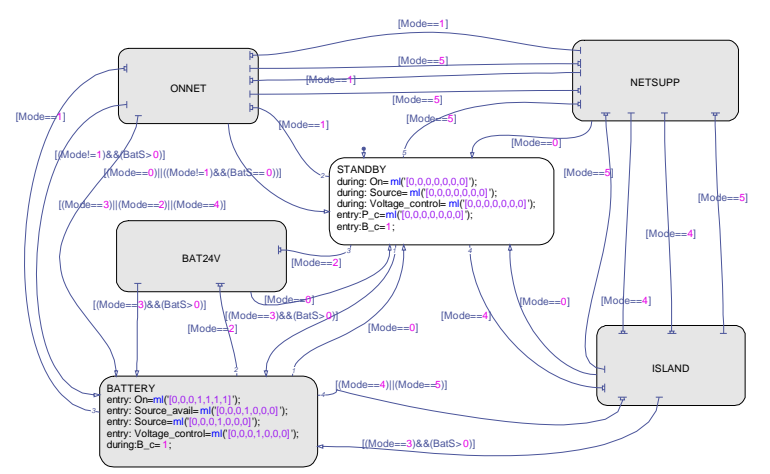

Figure 11. Stateflow representation of the power management model.

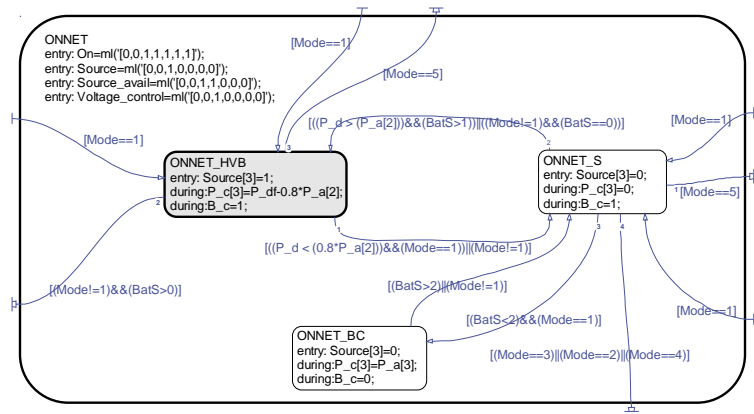

Figure 12. Stateflow representation of the ONNET operation mode.

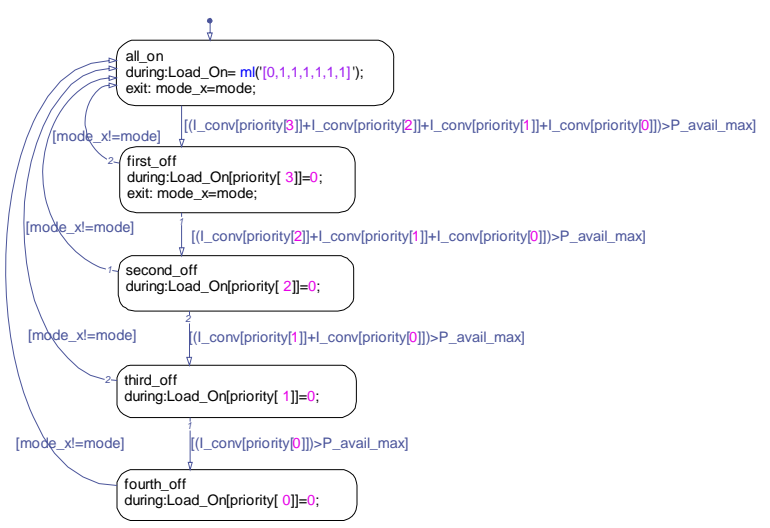

Figure 13. Algorithm for the load management. way to present such kind of algorithms. Stateflow upgrades the state automata representation of the system by mathematical and logical features, together with the possibility of including events. Furthermore, by designing algorithms in Stateflow it is not only possible to use the Matlab inherent automatic code generation (giving $\mathrm{C}$ code as a result), but also to enforce systematic approach on the designer. In Matlab/Simulink it is possible to exchange the Stateflow block with a s-function block, making it possible to evaluate the algorithms written directly in C-code, which is an important goal for the future use of the converter system model.

\section{Experimental and Simulation Results}

\subsection{Laboratory Set-up}

Experiments were performed on the custom design hardware, with the master and converter control units using TI TMS320F2809 microcontroller. The algorithms for voltage and current control were executed in $25 \mu$ s time interval, whereas power management algorithm was executed in $10 \mathrm{~ms}$ time interval. The multi-converter system is shown Figure 14. Each power module contains an IGBT converter leg, like the one presented in Figure 3(a). The power modules are fully interchangeable, and thus oversized for the majority of converters. This makes the system more useful for the experimenting purposes.

\subsection{Simulation Results}

Unlike most of the technical papers, simulation results follow the experimental ones. This is due to the fact, that the model and its operation are a result in the presented case. The model, containing all sub-systems described above is presented in Figure 17. The model additionally includes battery status model to serve as output for testing operation in case of various battery states (low, full, ...). Simulation results in Figure 18 present a runtrough over all the active operating states (presented in Table 1), where states are represented by the value of the variable mode $(0-$ system turned off, $1-$ ONNET,

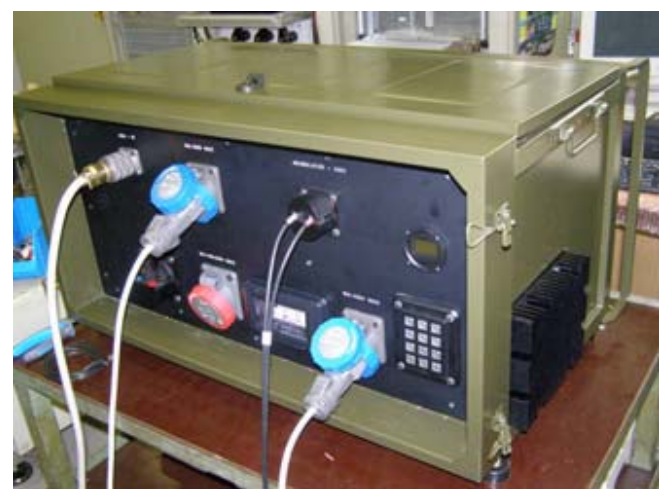

Figure 14. Functional prototype of the system. 


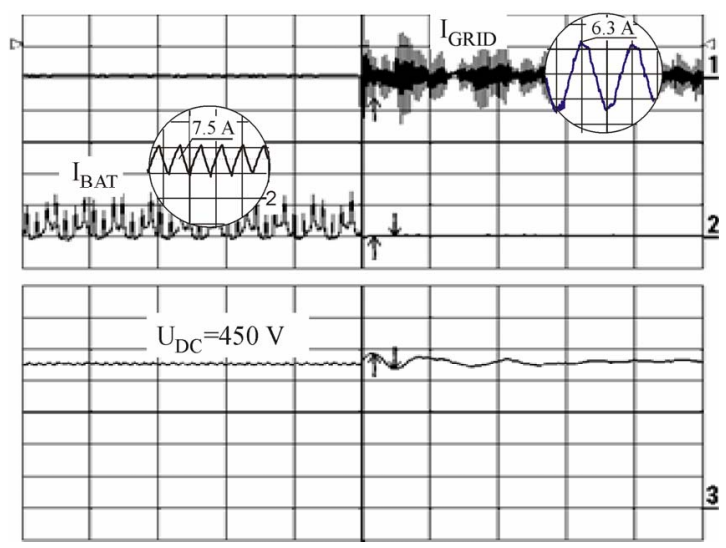

Figure 15. Transfer from C3 to C2 (1-battery current, $\mathrm{I}_{\mathrm{BAT}}{ }^{-}$ $5 \mathrm{~A} /$ div; 2-current to grid, $\mathrm{I}_{\mathrm{GRID}} 5 \mathrm{~A} / \mathrm{div}$; 3-DC-link voltage, $\mathrm{U}_{\text {DC }} 100 \mathrm{~V} / \mathrm{div}, \mathrm{x}$-axis 1s/div).

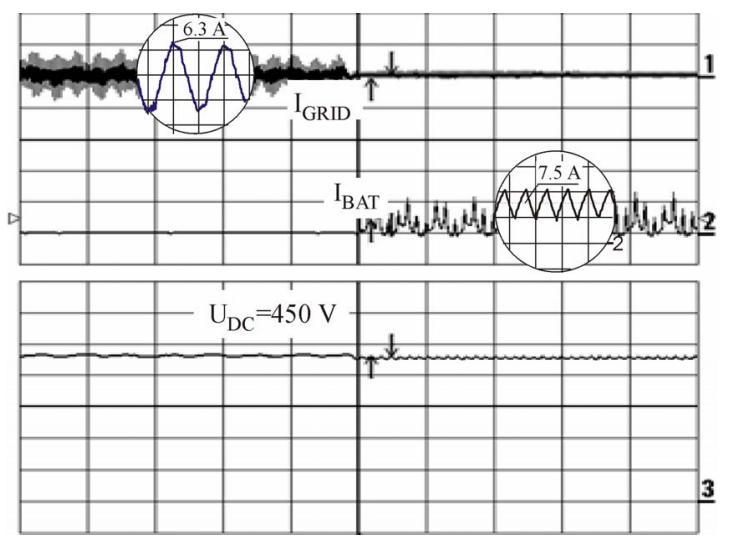

Figure 16. Transfer from $\mathrm{C} 2$ to $\mathrm{C} 3$ (1-battery current, $\mathrm{I}_{\mathrm{BAT}^{-}}$ 5A/div; 2 - current to grid, $I_{\text {GRID }}-5 \mathrm{~A} /$ div; 3 - DC-link voltage, $\mathrm{U}_{\mathrm{DC}}-100 \mathrm{~V} / \mathrm{div}, \mathrm{x}$-axis $\left.1 \mathrm{~s} / \mathrm{div}\right)$.

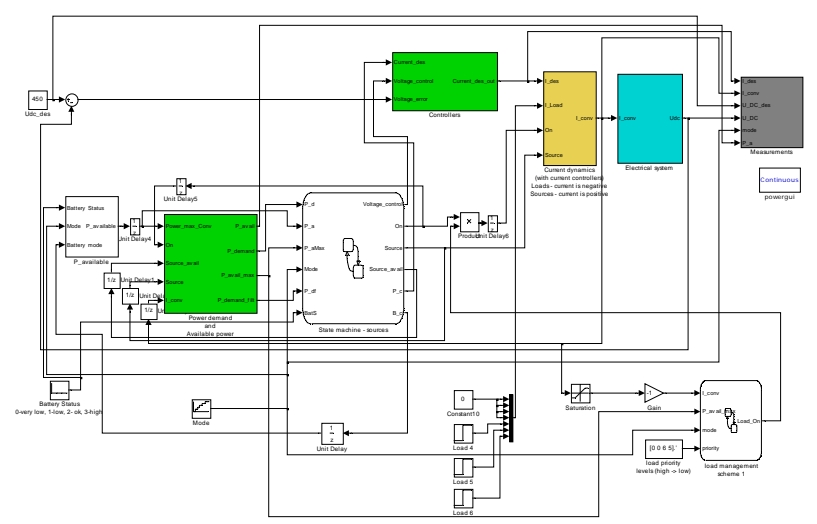

Figure 17. Complete Matlab/Simulink model of converter system.

2-BAT24V, 3-BATTERY, 4-ISLAND, 5-NETSUPP). Positive currents would be the ones flowing from the converter to the DC-link. The effects of applied load management scheme are also presented. Converters C5 and $\mathrm{C} 6$ are turned-on by user and turned-off by the load
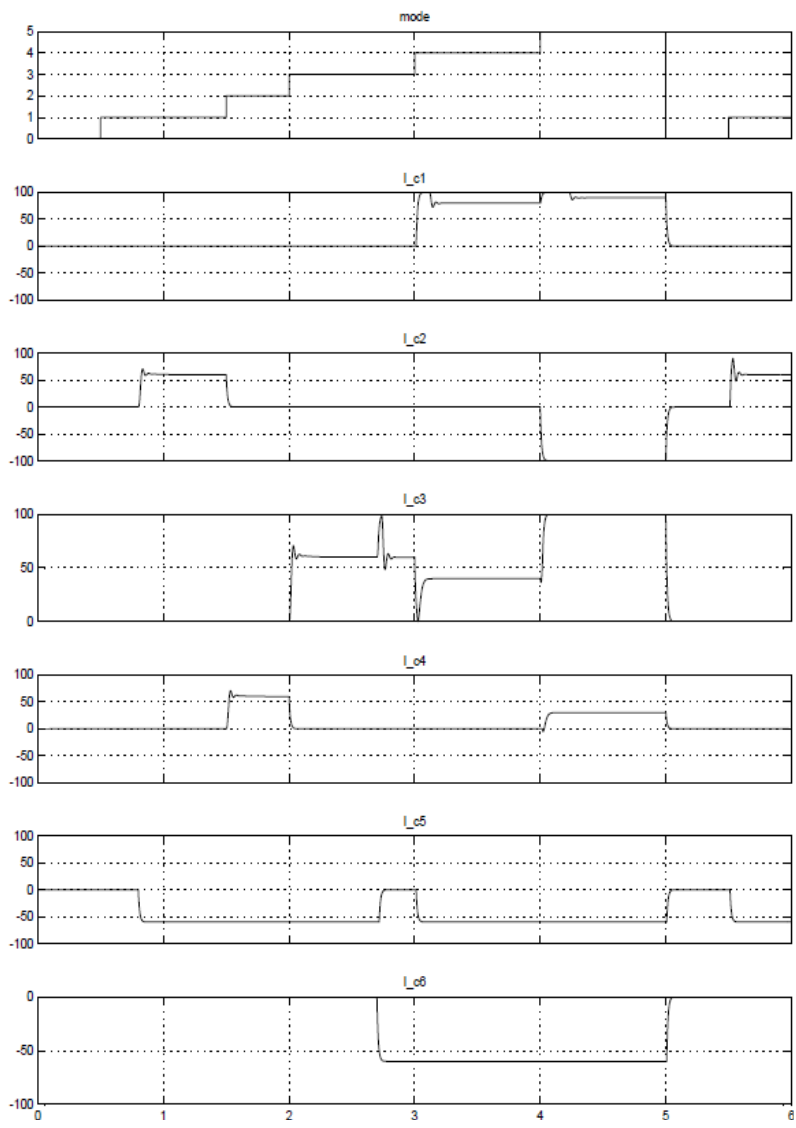

Figure 18. Simulation results of operation.

management algorithm based on the priorities set to them. In the presented case the system is first turned off. Then the ONNET mode is applied, but since there are no power demands presented by attached loads, the power does not have to be provided by converter $\mathrm{C} 2$ (which is voltage-controlled). The power demand for the load attached to the converter $\mathrm{C} 5$ occurs after $0.8 \mathrm{~s}$ of operation and is immediately covered by converter $\mathrm{C} 2$. In next step the operation mode is changed to BAT24V. In this mode converter $\mathrm{C} 2$ is turned off and converter $\mathrm{C} 4$ is turned on. The power demand presented by load attached to converter C5 is covered from the $24 \mathrm{~V}$ battery connected to converter $\mathrm{C} 4$. When the mode of operation is changed to BATTERY, converter C 3 is turned on and converter C4 turned off. The power is now provided by high-voltage battery, connected to converter $\mathrm{C} 3$. In the next step, the converter C6 is turned on. Because the priority of load connected to converter $\mathrm{C} 5$ is lower than the priority of the load connected to C6, converter C5 is turned-off. In this case there is also no possibility to use an additional power source, since the mode BATTERY presents the case of autonomous operation. For the case of higher power demand, with no demand for quiet operation, the operation mode ISLAND is used, which is applied in the next step. Additional power is now provided by converter 
$\mathrm{C} 1$ and the converter $\mathrm{C} 5$ is consequently turned-on again. In order to achieve the slower high-voltage battery discharge, most of the power is provided by converter $\mathrm{C} 1$ and only a small portion by converter C3. Finally, the last one of modes, NETSUPP, is applied. In this operation it is expected that converter $\mathrm{C} 2$ is supporting the power grid by the maximal possible power (this is presented by the negative current for this controller), which is, together with the power required by loads connected to converters C5 and C6 provided not only by the generator (converter $\mathrm{C} 1$ ), but also by the $\mathrm{C} 3$ and in smaller portion by $\mathrm{C} 4$. At the end of test the system is turned-off and converters $\mathrm{C} 5$ and $\mathrm{C} 6$ are also turned-off.

To demonstrate the possibility of restarting at the end of simulation test the mode is again changed to ONNET.

\section{Conclusions}

Research and development on the equipment are still active, especially in the power management schemes to be applied. In future we hope to be able to present more contributions in this direction. However, in order to be able to analyze the operation also off-line, a model of the system was created and is now under evaluation. It can serve as a good study and analysis tool. Next steps in its development will include the possibility of use in HIL (Hardware-In-the-Loop) and SIL (Software-In-the-Loop) systems. The model has to be improved further by extending the dynamic model from the currently used linear approximation to the non-linear representation. It was also considering the creation of a simple interface for the introduction of s-functions. In practice it is often impossible to measure them, especially because the currents into the DC-link capacitors would have to be measured. Transformation values obtained from the input currents or other (converter-internal) variables would have to be used instead. However, use of DC-link currents can be used in the model of the presented kind, which is a further advantage of its use.

Special attention will be given to the development of the presented system, apart from its main purpose, can be also used as a valuable research and teaching tool, power and energy management schemes, with the focus on the cost functions and introduction of renewable power sources.

\section{REFERENCES}

[1] L. Solero, A. Lidozzi and J. A. Pomilio, "Design of Multiple-Input Power Converter for Hybrid Vehicles," IEEE Trans. on Power Electronics, Vol. 20, No. 5, September 2005, pp. 1007-1015.

[2] P. Pisu and G. Rizzoni, "A Comparative Study Of Supervisory Control Strategies for Hybrid Electric Vehicles,"IEEE Transactions on Control Systems Technology, Vol. 15, No. 3, May 2007, pp. 506-518.

[3] H. Dehbonei, S. R. Lee, S. H. Ko and C. V. Nayar, "A Control Approach and Design Consideration of PV/Diesel Hybrid Distributed Generation System Using Dual Voltage Source Inverter for Weak Grid," SICE-ICASE International Joint Conference 2006, Oct. 18-2 1, 2006 in Bexco, Busan, Korea, pp. 672-677.

[4] A. Hajizadeh and M. A. Golkar, "Control of Hybrid Fuel Cell/Battery Distributed Power Generation System with Voltage Sag Ride-Through Capability," 2nd IEEE International Conference on Power and Energy (PECon 08), December 1-3, 2008, Johor Baharu, Malaysia, pp. 463-467.

[5] A. Molderink, V. Bakker, J. L. Hurink and G. J. M. Smit, "Algorithms for Balancing Demand-side Load and Micro-generation in Islanded Operation," 19th International Conference on Systems Engineering, pp. 115-120.

[6] Z. Jiang, "Power Management of Hybrid Photovoltaic Fuel Cell Power Systems," IEEE Power Engineering Society General Meeting, 18-22 June, 2006, pp. 1-6.

[7] C. Abbey, J. Robinson and G. Joós, "Integrating Renewable Energy Sources andSstorage into Isolated Diesel Generator Supplied Electric Power systems," EPE-PEMC 2008, 1-3 Sept. 2008, pp. 2178-2183.

[8] J. Zhuo, C. Chakrabarti, K. Lee and N. Chang, "Dynamic Power Management with Hybrid Power Sources," in: 44th ACM/IEEE Design Automation Conference, DAC '07 , 4-8 June 2007, pp. 871-876.

[9] M. E. Torres-Hernández and M. Vélez-Reyes, "Hierarchical Control of Hybrid Power Systems," in: 11th IEEE International Power Electronics Congress, 2008. CIEP 2008, 24-27 Aug. 2008, pp. 169-176.

[10] A. A. Ferreira, J. A. Pomilio, G. Spiazzi and L. de Araujo Silva, "Energy Management Fuzzy Logic Supervisory for Electric Vehicle Power Supplies System," IEEE Transactions on Power Electronics, Vol. 23, No. 1, January 2008, pp. 107-115 